\title{
Evaluation of Attitudes and Using About Complementary and Alternative Medicine of People Aged 18 and Older In Antalya
}

\author{
Cem Kiran \\ Department of Family Medicine, Akdeniz University Hospital, Akdeniz University, Faculty of \\ Medicine, Dumlupinar Boulevard, Akdeniz University Campus, 07058 Konyaalti, Antalya, Turkey \\ Email: drcem_kiran@yahoo.com.tr \\ Melahat Akdeniz \\ Department of Family Medicine, Akdeniz University Hospital, Akdeniz University, Faculty of \\ Medicine, Dumlupinar Boulevard, Akdeniz University Campus, 07058 Konyaalti, Antalya, Turkey \\ Email: melahatakdeniz@gmail.com \\ Ethem Kavukcu \\ Department of Sports Medicine, Akdeniz University Hospital, Akdeniz University, Faculty of \\ Medicine, Dumlupinar Boulevard, Akdeniz University Campus, 07058 Konyaalti, Antalya, Turkey \\ Email:ethemkavukcu@gmail.com
}

*These authors contributed equally to this work. The research is financed by the authors.

\begin{abstract}
Objectives: It is aimed to evaluate the information, attitudes and utilization rates of complementary and alternative medicine forms of individuals aged 18 years and over who apply two outpatient clinics affiliated to Department of Family Medicine of Akdeniz University Hospital.

Materials and Forms: This cross-sectional and descriptive study has been conducted by way of faceto-face questioning. The statistical analyses have been performed using SPSS ver. 22.0. The sample size has been calculated as 400, with the "OpenEpi.Version 3 Open Source Calculator", with the reliability level calculated as $99 \%$, the frequency rate as $50 \%$, the confidence interval as $5 \%$ and the sample error as 0.05 . The Chi-Square, Kruksal-Wallis test and Spearman correlation analysis were used.

Results: A total of 417 people participated in the study. Rate of CAM usage of participants was $23.5 \%$. Approximately $10 \%$ of respondents reported using CAM forms in addition to their prescription drugs. Phytoterapy which contains the herbal products, was used most common CAM method with $73.9 \%$. Other CAM forms used by participants were ozone treatment (9\%), hidrotherapy $(4.1 \%)$, hirudotherapy (9\%) and meditation (4\%). It was reported that $20.4 \%$ of the participants for respiratory symptoms, $12 \%$ for digestive system symptoms, $7 \%$ for pain and $6.2 \%$ for weight loss preferred CAM as the first treatment.

Conclusion: CAM is being used by more and more people all over the world and in Turkey. The proportion of people using CAM in Turkey is lower than in developed countries. Most patients are hesitant to provide information to their physicians about CAM treatments they are using, thinking they will not approve. Further studies on the use of CAM forms in Turkey are needed.
\end{abstract}

Keywords: Complementary Medicine, Alternative Medicine, CAM, prevalence.

DOI: $10.7176 /$ JSTR/5-4-21

\section{Introduction}

Today, advances in technology and modern medicine have made progress in the diagnosis and treatment of many diseases. However, there is currently no cure for several chronic diseases ${ }^{[1]}$. Because of modern treatments are not effective enough, and inadequate access to care, side effects of conventional treatments, patients can seek alternative treatment forms. Complementary and alternative medicine (CAM) includes diverse modalities and products that are not integral part of conventional medicine ${ }^{[2]}$. Recent studies indicate that CAM is being used increasingly worldwide and studies show that the prevalence of CAM use varies between $5 \%$ to $74.8 \%$ in different countries ${ }^{[3]}$. 
CAM can be used either directly for the purpose of treatment or to support the current treatment. The patients believe that CAM modalities are harmless and are not reported to their physicians. Although some of them are useful, certain CAM may also put person's life in danger because of interacting with drugs used for another illness. It is important that family physicians are aware that patients may use these treatment modalities ${ }^{[4-6]}$.

World Health Organization (WHO) recommends that research on evidence-based scientific forms for complementary medical practice should be encouraged, practices should be carried out by trained and licensed persons, and national legislation should be developed in such a way that these practices will not be exploited ${ }^{[7]}$.

In the context of WHO's recommendations, countries are making arrangements to control CAM practices. In Turkey, the regulation issued by the Ministry of Health in 2014 has taken the decision to standardize CAM applications ${ }^{[8]}$. This regulation has legalized that all CAM applications to be standardized, scientifically investigated and implemented only by health personnel under the supervision of physicians, dentists and practitioners who have received training for CAM applications. It has also been suggested that CAM forms should not be substituted for the standard treatment of the current disease and that it should be stated in the informed consent form signed by the patient ${ }^{[8]}$. CAM practices should be beneficial for the health and quality of life of the patient, and the results should be consistent with the principles of usefulness and non-harm ${ }^{[8]}$.

The CAM forms approved by the Ministry of Health are acupuncture, apitherapy, phytotherapy, hypnosis, hirudotherapy, homeopathy, chiropractic, cup application, larval application, mesotherapy, prolotherapy, osteopathy, ozone therapy, reflexology and music therapy ${ }^{[8]}$.

One of the responsibilities of family physicians is to protect their patients from harmful practices both in their own practice and in other health care settings within the scope of advocacy ${ }^{[9]}$. In order to be able to perform this task, they need to know the other treatment forms used by their patients in addition to conventional medicine practices, and be aware of the benefits and potential risks of these forms on their health ${ }^{[5,6]}$. Most patients are reluctant to inform their physicians about the CAM treatments they use because they think they will not approve them. Family physicians should encourage their patients to talk about CAM forms they use ${ }^{[10]}$.

CAM usage rates, CAM forms used, and reasons for using CAM were investigated in studies conducted in different countries. There is no study on the rates of use of CAM forms in the general population in Turkey. Studies have generally been based on the use of CAM modalities in private groups and in people with chronic illnesses ${ }^{[11,12]}$. In this study, we aimed to evaluate the awareness, utilization aims and usage rates of CAM forms in adults over 18 years old who applied to two outpatient clinics affiliated to Department of Family Medicine of Akdeniz University Hospital.

\section{Materials and Methods}

This study was designed to evaluate using rate and, attitudes about complementary and alternative medicine in all adults over 18 years old, who applied to two outpatient clinics. One of the outpatient clinics is within a university hospital, the other is within the community. The size of the sample for this study, which we designed as cross-sectional and descriptive, was calculated as 400 with the "OpenEpi.Version 3. open source calculator", with the reliability level taken as $99 \%$, the frequency percentage as $50 \%$, the confidence interval as $5 \%$ and the sample error as 0.05 .

The literature was searched with the keywords complementary medicine, alternative medicine, primary care, CAM, knowledge, attitude, and then a questionnaire was developed. The questionnaire was implemented on 417 volunteers, who had applied to the outpatient clinics for any reason, between the months of April - July 2016 ( 3 months), and who had agreed to participate in the study and given their consent. The questionnaire was administered by face to face interview.

The statistical analyses were performed using SPSS ver. 22.0. Mean and standard deviation was used in the depictive analyses, while the Chi-Square and Kruskal-Wallis tests and Spearman correlation analysis were used for the analysis of categorical data. The $\mathrm{P}<0.05$ value was deemed to be significant. Ethical approval was obtained from the Ethics Committee of Clinical Investigations of the Faculty of Medicine of Akdeniz University on December 9, 2015 with the decision number 365.

\section{Results}

Four hundred and seventeen people participated in the study. Study population consistent of $73.6 \%$ female, $26.4 \%$ men, $68.3 \%$ married, $66.6 \%$ college education, and $71.4 \%$ earning less than $\$ 1000$ per month. Sociodemographic data of the participants are given in Table 1. 
Table 1. Sociodemographic data of the participants.

\begin{tabular}{|c|c|c|c|}
\hline \multicolumn{2}{|c|}{ Sociodemographic data } & number (n) & Percent (\%) \\
\hline \multirow{4}{*}{ Age groups } & $19-26$ & 51 & 12,2 \\
\hline & $27-49$ & 244 & 58,5 \\
\hline & $50-64$ & 98 & 23,5 \\
\hline & $\geq 65$ & 24 & 5,8 \\
\hline \multirow{4}{*}{ Marital status } & Single & 90 & 21,6 \\
\hline & Maried & 285 & 68,3 \\
\hline & Divorsed & 31 & 7,4 \\
\hline & Widov & 11 & 2,6 \\
\hline \multirow{3}{*}{ Education level } & Primary education & 46 & 11.0 \\
\hline & High school & 93 & 22,3 \\
\hline & College & 278 & 66,6 \\
\hline \multirow[t]{4}{*}{ Total income level } & Low (less than $\$ 300$ per month) & 33 & 7,9 \\
\hline & Medium (\$300-\$1000 per month) & 265 & 63,5 \\
\hline & High ( $\$ 1000$ per month and above) & 99 & 23,7 \\
\hline & No response & 20 & 4,8 \\
\hline \multirow{4}{*}{ İnsurance status } & SGK (State insurance) & 401 & 96,2 \\
\hline & Private insurance & 7 & 1,7 \\
\hline & No response & 3 & 0,7 \\
\hline & No insurance & 6 & 1,4 \\
\hline
\end{tabular}

Ninety-eight people (23.5\%) who participated in the study reported using at least one CAM form in the last one year. Eighteen percent of female participants and $5.5 \%$ of male participants reported using at least one CAM form. This difference between CAM using rates between men and women was not statistically significant (Pearson chi-square test, $\mathrm{p}>0.05$ ). The most commonly used CAM method for all participants was phytotherapy.

About half of the participants had at least one chronic illness, and 19,9\% had more than one chronic disease (multimorbitide). Distribution of participants with chronic disease according to disease types is shown in Table 2.

Table 2. Distribution of participants with chronic illnesses according to disease types

\begin{tabular}{|l|c|c|c|}
\hline Chronic disease & Female $(\boldsymbol{\%})$ & Male $(\boldsymbol{\%})$ & Total (\%) \\
\hline Hypertension & 15 & 17 & 32 \\
\hline Hypothyroidism & 18 & 2 & 20 \\
\hline Diabetes Mellitus & 6 & 14 & 20 \\
\hline Cardiac disease & 7 & 9 & 16 \\
\hline Mental disease & 7 & 4 & 11 \\
\hline Pulmoner disease & 6 & 1 & 7 \\
\hline Neurological disease & 5 & 2 & 7 \\
\hline Blood disease & 5 & 0 & 5 \\
\hline Renal disease & 1 & 4 & 5 \\
\hline Liver disease & 1 & 3 & 4 \\
\hline Cancer & 2 & 0 & 2 \\
\hline
\end{tabular}

Sixty four percent of people with chronic disease were on regular medication. The mean number of medicine used per users was 1.9 (min: 1 - max: 4, SD: 1.1). The rate of participants using one form of CAM in addition to prescription medicines was $9.6 \%$. The most used form of CAM was herbal products 
(\%73.9). Other forms of CAM used by participants were ozone therapy (9\%), hirudotherapy (9\%), hydrotherapy $(4.1 \%)$, and meditation $(4 \%)$.

In the study, the most known CAM method was phytotherapy (56.1\%) and the least known TAT method was Maggot (larval) treatment (3\%). The rate of awareness of CAM forms by participants is given in Table 3.

Table 3. Participants' recognition rates of CAM forms.

\begin{tabular}{|l|c|c|c|}
\hline CAM Forms & $\begin{array}{c}\text { Percentage of people who } \\
\text { reported information }\end{array}$ & Form of CAM & $\begin{array}{c}\text { Percentage of people who } \\
\text { reported information }\end{array}$ \\
\hline Phytotherapy & $\mathbf{5 6 \%}$ & Chiropractic & $27 \%$ \\
\hline Acupuncture & $51 \%$ & Osteopathy & $23 \%$ \\
\hline Cup application & $40 \%$ & Mesotherapy & $15 \%$ \\
\hline Hirudotherapy & $38 \%$ & prolotherapy & $12 \%$ \\
\hline Ozone treatment & $34 \%$ & Apitherapy & $7 \%$ \\
\hline Homeopathy & $32 \%$ & Maggot therapy & $3 \%$ \\
\hline
\end{tabular}

The main source of information for participants about CAM was the media (68\%). Other important sources of information were the friends and family members (35\%), and health workers (32\%).

The participants preferred to use the form of CAM in for upper respiratory tract symptoms, acute and chronic pain, weight loss, skin symptoms, digestive system symptoms, urinary tract symptoms and psychological symptoms. The most commonly used CAM is phytotherapy $(97.6 \%)$ which contains herbal products such as honey, ginger, sage and lime.

Eighteen percent of of the participants who suffering from pain such as back pain, tooth pain, joint pain, and headache reported that they primarily used phytotherapy (39\%), hydrotherapy (19\%), acupuncture (19\%), chiropractic (19\%), meditation (14.2\%), and massage therapy (14.2\%) respectively.

Twelve percent of the participants with digestive symptoms reported that they were used any CAM form as initial treatment. All of these people prefer phytotherapy products. The rate of participants primarily used the CAM forms for weight loss was $6.2 \%$. The most frequently used CAM form for weight loss are phytotherapy $(60 \%)$ and acupuncture $(6.5 \%)$.

Only $4.5 \%$ of participants with skin symptoms such as pruritus, rash, eczema, hair loss, reported that they primarily used the CAM method. The most commonly used CAM form for dermatological problems is phytotherapy with a rate of $84.2 \%$.

Very few of the people (3.4\%) with urinary system problems or mental symptoms prefer the CAM therapies as initial treatment. Phytotherapy $(85.7 \%)$ was the most commonly used CAM form for urinary system problems, and phytotherapy (57.1\%) and meditation (35.7\%) were the aplications most commonly used by people with mental problems.

\section{Analysis of Categorical Data}

There was no statistically significant relationship between participants' marital status, place of residence, education levels, occupations, ages, income levels and use of CAM (Pearson Chi square test, $\mathrm{p}<0.05$ ). The use of CAM was found to be statistically significant in just alcohol-consuming people (pearson kisquare test, $\mathrm{p}<0.05$ ) with in both alcohol consuming and smoking people (Fisher's exact test, $\mathrm{p}<0.05$ ). There was a statistically significant relationship between pulmonary disease (Fisher's exact test, $p<0.05$ ) and psychiatric disease (Pearson chi-square test, $\mathrm{p}<0.05$ ) and CAM usage. The rate of CAM usage was higher in both diseases. But, no statistically significant relationship was found between the usege of CAM and other diseases.

The rate of CAM users among at least one medicine users was 32.8\%. The rate of CAM use among nonmedicine users was $18.9 \%$. People who are on continuous medication were using more CAM than those who did not use any medicines. As the number of medicine used increases, the rate of using CAM increases statistically (Pearson chi-square test, $\mathrm{p}<0.05$ ).

\section{Discussion}

Today, the use of CAM is increasing in our country in parallel with the world. In the studies conducted in different countries, frequency of CAM use, the CAM forms used and the reasons of CAM use were investigated.

In the literatüre, it has been reported that, women, those with high educational level, those with middle adulthood, and those with higher income levels are more commonly used CAM forms ${ }^{[3,4,6]}$. In this study, 
statistically significant relationship was not found between participants age, education levels, occupations, income levels and use of CAM.

CAM users report that information about CAM forms is obtained from family members, friends, media, internet, health workers, pharmacists and places selling health products ${ }^{[12]}$. Participants in this study reported that they obtained the information about CAM forms primarily from the media (68\%), and from their family and friends (35\%). The rate of participants who obtained information from health workers was $32 \%$. No participant reported that the physicians offered a CAM form for treatment of medical conditions.

As opposed to our study, In the study conducted by Ock SM et al. in South Korea, family and close friends $(66.9 \%)$ were the first sources of information about participants' CAM therapies. The media was the second source $(11,7 \%)$, physicians were the third source $(4,1 \%)^{[13]}$.

All of the participants reported that they had knowledge about at least one CAM form. The most known CAM forms were phytotherapy $(56 \%)$, acupuncture $(51 \%)$ and cup application $(40 \%)$. Individuals who have knowledge about CAM forms are more likely to use them.

In the study, the rate of participants reporting that they use at least one CAM method was $23.5 \%$. In a review of studies conducted in 15 countries, it has been found that the prevalence of CAM use in the whole world varies between $9.8 \%$ and $76 \%{ }^{[14]}$. In the US, the prevalence of CAM use in different studies ranges from $29 \%$ to $42 \%{ }^{[4]}$. The National Center for Complementary and Integrative Health reports that approximately $38 \%$ of adults and $12 \%$ of children use one of the CAM forms ${ }^{[2]}$. In the UK, the mean annual prevalence of CAM use is $41.1 \%(9.2-100 \%)$ and the mean lifetime prevalence of CAM use is $51.8 \%(29-71 \%)^{[15,16]}$. In Scandinavian countries, the prevalence of CAM use is $34 \%$ in Norway, $45 \%$ in Denmark and $49 \%$ in Sweden ${ }^{[17]}$. There is no study on the prevelance of CAM use in the general population in Turkey. The studies were conducted in selected patient groups or regions ${ }^{[11,21]}$.

The reason for the difference in the rates of CAM use among countries may due to the formal education about CAM in some countries. Western countries such as America, Australia, Germany and England have educational institutions for many CAM practices such as homeopathy, osteopathy, chiropractic. An increasing number of medical faculties have begun to include CAM practices in their pre-graduate curricula. Currently more than $30 \%$ of the countries are provided CAM education at university level ${ }^{[4]}$. In Turkey, there is not the formal education about CAM in level of faculty of medicine.

The most commonly used CAM form in our study were phytotherapy (73.9\%). CAM forms which were used less frequently were ozone therapy (9\%), hirudotherapy (9\%), hidrotherapy $(4.1 \%)$, and meditation (4\%). The most commonly used CAM form in the UK are herbal medications (64.2\%), homeopathy and acupuncture ${ }^{[16]}$. It has been reported that the most commonly used CAM forms in the US are natural products $(17.7 \%)$, deep breathing $(12.7 \%)$, meditation $(9.4 \%)$, chiropractic and osteopathy $(8.6 \%)$, massage $(8.3 \%)$ and yoga $(6.1 \%){ }^{2,19]}$. The most commonly used CAM form in Canada are mind-body and manipative treatment ${ }^{[20]}$. In Norway, the most commonly used CAM treatment forms are homeopathy, chiropractic, acupuncture and reflexology, respectively. In Denmark, Reflexology and massage and in Sweeden, massage are the most commonly used CAM forms ${ }^{[17]}$.

In our study, a statistically significant relationship was found especially between the use of CAM and respiratory system complaints (Fisher's exact test, p <0.05) and psychological symptom. Participants were found to prefer the most common herbal products (honey, ginger, sage, lime, etc.) (97.6\%) in upper respiratory tract complaints such as cough and sore throat. Likewise, most of the herbal products (Melisa tea, etc.) were preferred in mental complaints such as extreme sadness and anxiety.

There are different reasons for the preference of CAM usage in the literature studies. A large communitybased survey conducted in Australia found that Chinese herbal products were more commonly used for complaints such as colds, sore throat, and anxiety ${ }^{[21]}$. The most important reason for using CAM in South Korea are the prevention of disease and health promotion $(78.8 \%)^{[13]}$. In South Korea, $20 \%$ of participants reported that they used CAM for medical problems, $3.2 \%$ of those used CAM for weight loss, $2.9 \%$ of those used CAM for stress management. In the Czech Republic, at the top of the reasons for the use of CAM is prevention of diseases by $82 \%$. Only about $20 \%$ of CAM users use it for the purpose of therapeutic. The most common reasons of CAM use for therapeutic purposes are for treatment of respiratory system diseases $(35.0 \%)$ and musculoskeletal system diseases $(33.6 \%)^{[22]}$.

In our study, using of CAM was found to be statistically significantly higher in individuals consuming alcohol and in both alcohol consuming and smoking individuals. In a systematic review identifing behavioral patterns and characteristics of CAM users, it was found that individuals with excessive alcohol consumption in Australia resorted to CAM more often ${ }^{23}$. Similarly, a cross-sectional study conducted in the USA found that the use of CAM was more frequent in those with alcohol problems ${ }^{[24]}$. In USA, according to the results of the NHIS 2002 report, among adults over 18 who quit smoking using, CAM use is more than those who never is smoking ${ }^{[24]}$. 
In our study, a statistically significant relationship was found between the presence of chronic disease and use of vitamin, mineral and herbal nutritional support products classified as biologically based therapies by NCCAM in complementary medical applications. The rates of using vitamins and supplements are higher for people with chronic diseases, than from people without chronic illness. It was also found that people with heart disease use less vitamins than those without heart disease. People with psychiatric illness used more vitamin and supplements than those without psychiatric illness. Similarly, in community-based studies in South Korea ${ }^{[13]}$, the Czech Republic ${ }^{[2]}$, and Australia ${ }^{[23]}$, it is reported that CAM are most often used to feel better, to increase the body's resistance against diseases, to cope with anxiety. Hunt and colleagues found that CAM forms, especially massage, aromatherapy and acupuncture, were preferred among women with anxiety or depression in the $\mathrm{UK}^{[25]}$.

\section{Conclusion}

CAM therapies are being used by more and more people all over the world and our country. The proportion of people using CAM in Turkey is lower than in developed countries. Most of the patients are hesitant to provide information to their physicians about CAM treatments they are using, considering they will not approve ${ }^{[26]}$. Patients should be encouraged to talk about CAM treatments they use avoiding accusatory attitudes.

The limitations of our work are that the number of samples is low and it is not done in the society to represent the whole country. The advantage is that the data can be collected by face-to-face interview method.

Declaration of conflicting interests: Autors have no conflict of interest.

\section{References}

[1] World Health Organization. Global Action Plan for The Prevention and Control of Noncommunicable Diseases 2013-2020.

[2] National Center for Complementary and Integrative Health (NCCIH). Complementary, Alternative, or Integrative Health: What's In a Name? Available at: https://nccih.nih.gov/health/integrative-health (accessed March 2018)

[3] Frass M, Strassl RP, Friehs H, Müllner M, Kundi M, Kaye AD. Use and Acceptance of Complementary and Alternative Medicine Among the General Population and Medical Personnel: A Systematic Review. The Ochsner Journal, 2012;12:45-56.

[4] Ernst E. Prevalence of use of complementary/alternative medicine: a systematic review. Bull Word Health Organ. 2000;78(2):252-7.

[5] Blackman JA. Are you ready to discuss complementary and alternative medicine? Family Practice Management, 2007;14(7):26-32,

[6] Steyer TE. Complementary and alternative medicine: A primer. Family Practice Management, 2001;8(3):37-22

[7] WHO Traditional Medicine Strategy 2014-2023. Available at http://apps.who.int/iris/bitstream/10665/92455/1/9789241506090_eng.pdf?ua=1 (accessed March 2018)

[8] Sağlık Bakanlığı Geleneksel ve Tamamlayıcı Tıp Uygulamaları Daire Başkanlığı Yönetmeliği. Available at http://www.saglik.gov.tr/SHGM/belge/1-38459/yonetmelik. html (accessed March 2018)

[9] The European Definition Of General Practice / Family Medicine. WONCA EUROPE 2011 Edition

[10] Palinkas LA. The Use of Complementary and Alternative Medicine by Primary Care Patients $J$ Fam Pract. 2000;49(12):1121-1130 
[11] Akan H, Izbirak G, Kaspar EÇ, Apaydin Kaya Ç et al. Knowledge and attitudes towards complementary and alternative medicine among medical students in Turkey. BMC Complementary and Alternative Medicine 2012;12:115

[12] Robinson A, Cooper S. Trusted Information Sources: The Preferred Option for Complementary and Alternative Medicine Users. Complementary Health Practice Review, 2007; 12(2):120-138

[13] Ock SM, Choi JY, Cha YS, Lee JB et al. The Use of Complementary and Alternative Medicine in a General Population in South Korea: Results from a National Survey in 2006. J Korean Med Sci 2009; 24: 1-6

[14] Harris PE, Cooper KL, Relton C, Thomas KJ. Prevalence of complementary and alternative medicine (CAM) use by the general population: a systematic review and update. Int J Clin Pract 2012; 66(10): 924-939.

[15] Hunt J.K, Coelho F.H, Wider B, Perry R, Hung K.S, Terry R, Ernst E. Complementary and Alternative Medicine Use in England: Results From a National Survey. Int J Clin Pract, 2010;64(11):1496-1502

[16] Pusadzki P, Watson LK, Alotaibi A, Ernst E. Prevalence of use of complementary and alternative medicine (CAM) by patients/consumers in the UK: systematic review of surveys. Clinical Medicine 2 013;13(2):126-31

[17]Hanssen B, Grimsgaard S, Launsø L, Fønnebø V, Falkenberg T, Rasmussen NKR (2005) Use of complementary and alternative medicine in the scandinavian countries, Scandinavian Journal of Primary Health Care, 2005;23(1): 57-62

[18] Çetin OB, Eskişehir'de tamamlayıcı ve alternatif tıp kullanımı. Sosyoekonomi. 2007;2:89- 106

[19] Passarelli T. Complementary and Alternative Medicine in the United States. Erişim: https://case.edu/med/epidbio/mphp439/complimentary_meds.pdf

[20] Sunjka ML, Pejcic A, Jakovljevic M. Utilization patterns of complementary and alternative medicine in Australia, Canada and the United States: popularity of dietary supplements, mindbody and manipulative therapies. Farmeconomia. Health economics and therapeutic pathways 2017; 18(1): 15-20.

[21]Zang L.A. Complementary and Alternative Medicine Use in Australia: A National PopulationBased Study. Division of Chinese Medicine School of Health Sciences RMIT University, August 2006, 1-343

[22] Pokladnikova J, Selke-Krulichova I. Prevalence of Complementary and Alternative Medicine Use in the General Population in the Czech Republic. Forsch Komplementmed 2016;23:22-28

[23] Jacobson G.I, White R. M, Smith C. T, Smith B, Wells S.T, Gackstetter D.G, Boyko J.E. SelfReported Health Symptoms and Conditions Among Complementary and Alternative Medicine Users in a Large Military Cohort. AEP, 2009;19(9):613-622

[24] Barnes M. P, Powell-Griner E, McFann K, Nahin L.R. Complementary and Alternative Medicine Use Among Adults: United States, 2002. NHIS Advance Data, 2004;(343):1-19.

[25] Hunt K.J, Coelho H.F, Wider B, Perry R, Hung S.K, Terry R, Ernst E. Complementary and alternative medicine use in England: results from a national survey, Int $\mathrm{J}$ Clin Pract, 2010;64(11):1496-1502

[26]Thomson P, Jones J, Evans JM, Leslie SL. Factors influencing the use of complementary and alternative medicine and whether patients inform their primary care physician, Complement Ther Med. 2012;20(1-2):45-53. 